\title{
Investigation of Bed Joint Reinforcement Influence on Mechanical Properties of Masonry under Compression
}

\author{
Lukasz Drobiec \\ Department of Building Structures, Faculty of Civil Engineering, Silesia University of Technology, Gliwice 44-100, Poland
}

\begin{abstract}
The results of investigations of compressed reinforced masonry walls subjected to axial compression are presented. Tests were carried out using specimens made of clay bricks and cement-lime mortar. As reinforcement, smooth and spiral twisted longitudinal rods, two types of structural wire mesh and truss type reinforcement were used. Two percentages of bed joint reinforcement, about $0.1 \%$ and $0.05 \%$ were applied. For each type of reinforcement, three masonry walls were tested. Additionally, nine unreinforced models were also tested. The main aim of the investigations presented is to determine the effect of different types of reinforcement on the load capacity and failure. Measurement of the strains of reinforcing bars permitted the recording of the strain level at the moment of crack appearance and also at the moment of failure.
\end{abstract}

Key words: Reinforced masonry, bed joint reinforcement, compressed masonry.

\section{Introduction}

Reinforcement has been used in masonry structures for about the last 200 years. Bed joint reinforcement is usually used for in-plane bending elements (like masonry lintels, walls affected by considerable deflections of floors) [1-7]. Moreover, it could be used in places of stress concentration (corners of window opening) [1, 4-8] and in wall areas under concentrated loads [6]. Of course, reinforcement is also used in elements endangered by shrinkage or thermal stresses [1, 8], or a horizontal load (wind load) [5]. In building practice, bed joint reinforcement is also used in buildings with timber floors where it takes over the stress irregularity from the rim under the wall plate [1, 4-6, 9]. Moreover, bed joint reinforcement is also used for reducing of scratching $[4,10-11]$ protecting against seismic and paraseismic influences [7] and for improvement of masonry mechanical properties [11]. All the above cases of bed joint reinforcement application show that it is usually used in elements loaded mostly vertically. Unfortunately, the research

Corresponding author: Drobiec Lukasz, Ph.D., C.Eng., research fields: concrete structures and masonry structures. E-mail: lukasz.drobiec@polsl.pl. into compressed masonry with the reinforcement situated in the bed joints comprises only a few levels of reinforcement percentage. Most investigations concern unreinforced masonry specimens under compression. Tests of vertically compressed reinforced masonry wallettes are presented. Four types of reinforcement in the form of longitudinal bars and structural wire mesh were used. The influence of such types of reinforcement on the load capacity, deformability and crack resistance was determined. Among other things, the influence of longitudinal bars as opposed to wire mesh on the failure form was observed. Measurement of the strain of the reinforcing bars permitted the measurement of the strain level at the moment of crack appearance and also at the moment of failure.

\section{Test Models}

Investigations were carried out using test specimens with overall dimensions of 1,265 mm $\times 1,030 \mathrm{~mm} \times$ $250 \mathrm{~mm}$ shown in Fig. 1. All elements were built of clay bricks (with dimensions $65 \mathrm{~mm} \times 120 \mathrm{~mm} \times 250$ $\mathrm{mm}$ ) and cement-lime mortars 1:1:6 (portland cement:lime:sand). The depth of mortar joints in masonry models was $10 \mathrm{~mm}$. Tests included 9 sets of 


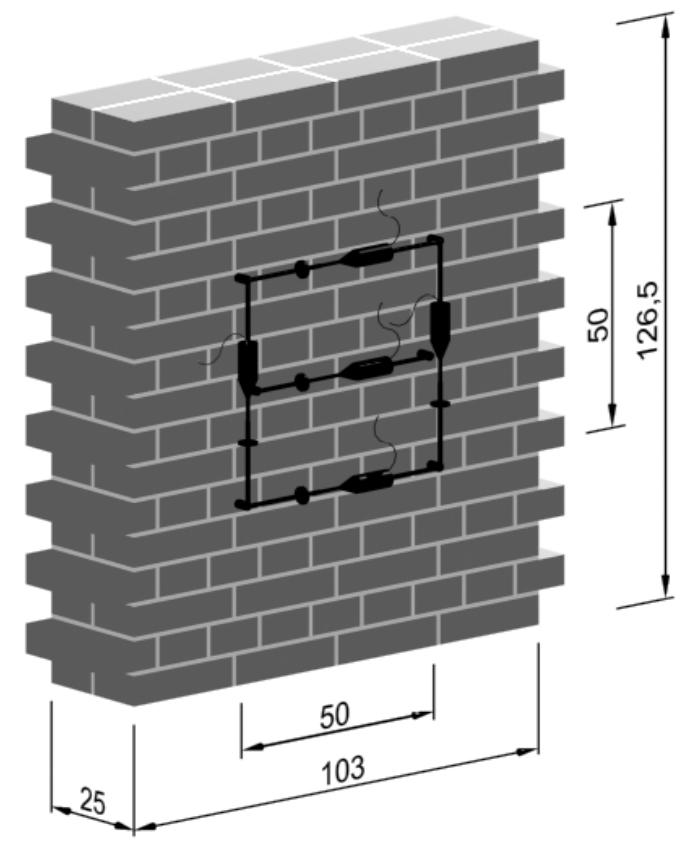

Fig. 1 Test specimen.

the unreinforced masonry specimens marked as "A" and 24 specimens with 4 types of reinforcement. Two reinforcement percentages: about $0.1 \%$ and about $0.05 \%$ were used. The first type of reinforcement was smooth stainless steel bars with a diameter of $6 \mathrm{~mm}$. The second was spiral twisted bars of one of the British systems for protection and strengthening of masonry fractures, with an outer diameter of about $6 \mathrm{~mm}$. The series of specimens with smooth bars was marked as "B" (BI-the reinforcement percentage about $0.05 \%$ and BII with reinforcement percentage $0.1 \%$ ). Reinforced series built with using of spiral bars were marked as "C" (CI and CII). Additionally, two types of wire mesh, stainless woven wire mesh with bars of diameter $4 \mathrm{~mm}$ (spacing between bars $40 \mathrm{~mm} \times 40 \mathrm{~mm}$ ) and welded wire mesh from zinc coated steel with the bars of diameter $1.25 \mathrm{~mm}$ and spacing in both directions $12 \mathrm{~mm} \times 12 \mathrm{~mm}$ were used. A series of specimens with wire mesh with $4 \mathrm{~mm}$ diameter of bars was marked as "D" (DI where the reinforcement percentage is $0.05 \%$ and DII where the reinforcement percentage is $0.1 \%$ ). Test wallettes with mesh with $1.25 \mathrm{~mm}$ diameter welded bars were marked as "E" (EI where the reinforcement percentage is $0.05 \%$ and EII where the reinforcement percentage is $0.1 \%$ ). As reinforcement in FI and FII series were used truss made from two longitudinal bars $5 \mathrm{~mm}$ in diameter and welded continuous wire diagonal $(4.5 \mathrm{~mm})$. In FI series reinforcement was placed in every 6th bed joint (the reinforcement percentage was about $0.05 \%$ ), while in FII series in every 3 rd bed joint (the reinforcement percentage was about $0.1 \%$ ). To ensure sufficient anchorage, flat bars $6 \mathrm{~mm} \times 20 \mathrm{~mm} \times 40 \mathrm{~mm}$ were welded on the ends of longitudinal rods, and flat bars 6 $\mathrm{mm} \times 20 \mathrm{~mm} \times 220 \mathrm{~mm}$ on the wire mesh ends.

All specimens were loaded during the investigations in a single cycle. Readings of load level and other measurements were made every $150 \mathrm{kN}$. For load force measurement, a dynamometer was used and for displacement reading inductive sensors with an accuracy of $0.002 \mathrm{~mm}$ were used. In specimens in the "B", "C" and "D" series, the measurement of rod deformation was made using foil strain gauges - one gauge in the middle of the length of each steel bar. Unfortunately, by reason of the bars' small diameter in models of the "E" series, it was impossible to use foil gauges for deformation measurement. Therefore, for these specimens the steel strains were not measured.

A general view of the test wallette and the inductive sensor placing is given in Fig. 1. All types of reinforcement with the strain gauge distribution is shown in Fig. 2. Simultaneously, material tests of compressive and tensile strength of the mortar according to EN 1015 [12] regulations were carried out. The compressive strength and modulus of elasticity of bricks to EN 772-1 [13] were also measured. The tensile strength of reinforcing steel according to Polish Standard PN-91/H-04310 [14] was measured. Additionally, using EN 1052-1 [15] the compressive strength and modulus of elasticity of masonry specimens were tested.

\section{Results of Material Properties Tests}

The values of the mortar properties and compressive strength of bricks are shown in Table 1. The compressive 


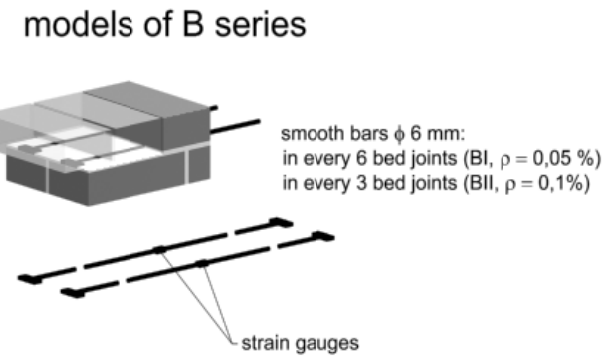

models of $\mathrm{C}$ series

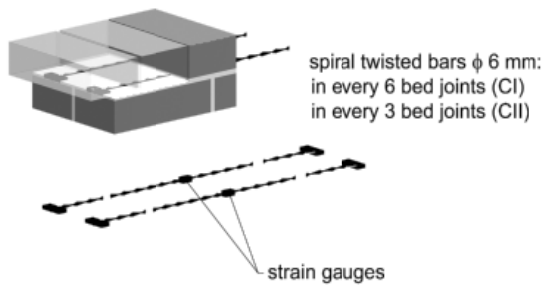

models of $\mathrm{F}$ series

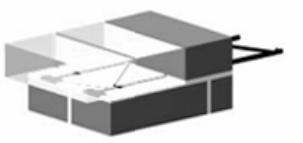

truss type reinforcement:

in every 6 bed joints $(\mathrm{FI}, \rho \approx 0,05 \%$ )

in every 3 bed joints (FII, $\rho \approx 0,1 \%$ )

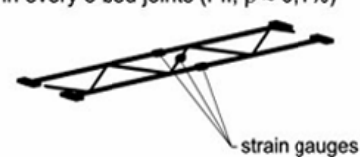

models of $D$ series

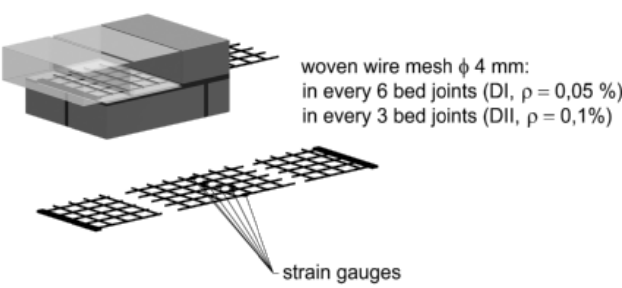

models of E series

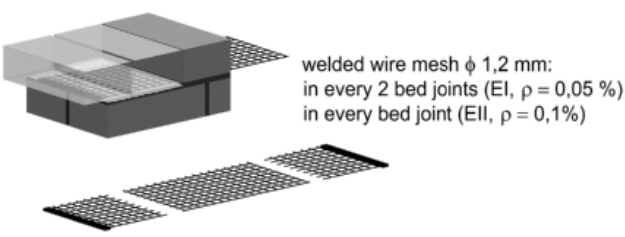

Fig. 2 Type of models reinforcement.

Table 1 Mortar and clay bricks properties.

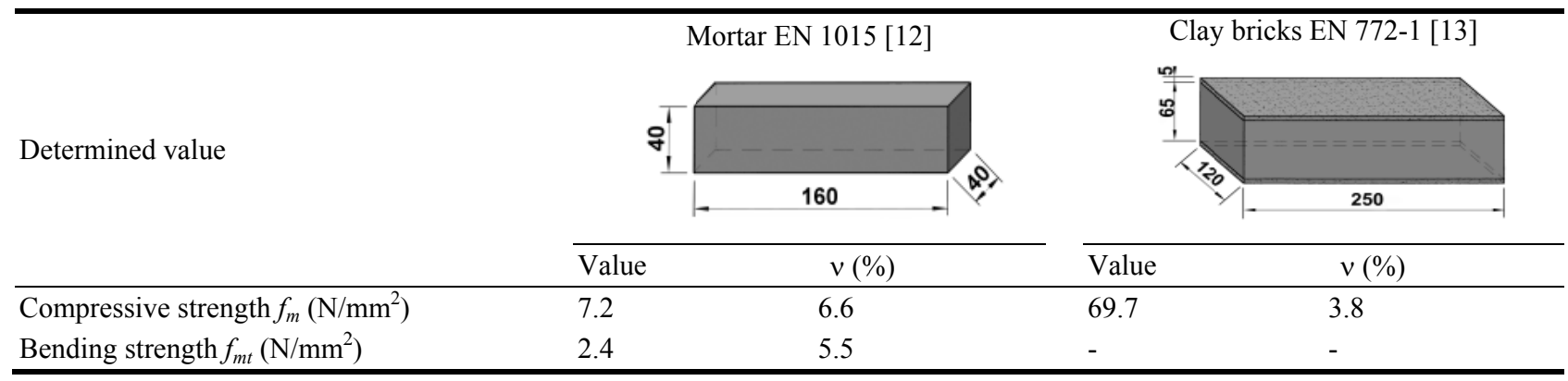

strength of the mortar was $7.2 \mathrm{~N} / \mathrm{mm}^{2}$, whereas the tensile strength in bending was about $2.4 \mathrm{~N} / \mathrm{mm}^{2}$. The compressive strength of bricks was about $69.7 \mathrm{~N} / \mathrm{mm}^{2}$. In Table 2, the values of ultimate tensile force, tensile strength, yield point and modulus of elasticity obtained for smooth and spiral twisted rods are given. The reinforcing bars strength-strain graph was acquired by using extensometer. The load capacity of masonry tests according to EN 1052-1 [15] were conducted. The mechanical properties of the masonry obtained in the tests are shown in Table 3.

\section{Results of Main Investigations}

In Table 4, the comparison of the average values of compressive strength, modulus of elasticity $E$ and Poisson's ratio for all unreinforced and reinforced 
Table 2 Smooth and spiral rod properties.

\begin{tabular}{|c|c|c|c|c|}
\hline \multirow{3}{*}{ Determined value } & \multicolumn{2}{|c|}{ Smooth rod PN-91/H-04310 [14] } & \multicolumn{2}{|c|}{ Spiral rod PN-91/H-04310 [14] } \\
\hline & & & & \\
\hline & Value & $v(\%)$ & Value & $v(\%)$ \\
\hline Rip force $(\mathrm{kN})$ & 23.1 & 0.9 & 8.4 & 0.8 \\
\hline Tensile strength $\left(\mathrm{N} / \mathrm{mm}^{2}\right)$ & 817 & 0.9 & 970 & 0.8 \\
\hline Yield point $\left(\mathrm{N} / \mathrm{mm}^{2}\right)$ & 760 & 0.7 & 910 & 0.7 \\
\hline Modulus of elasticity $\left(\mathrm{N} / \mathrm{mm}^{2}\right)$ & 204,000 & 1.2 & - & - \\
\hline
\end{tabular}

Table 3 Masonry properties.

Determined value

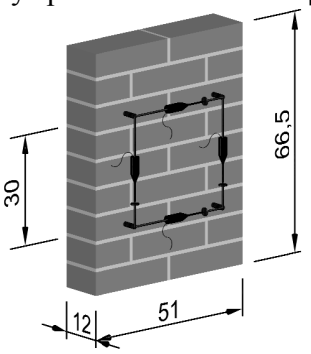

\begin{tabular}{lll}
\cline { 2 - 3 } & value & $v(\%)$ \\
\hline Compressive stress $\left(\mathrm{N} / \mathrm{mm}^{2}\right)$ & 15.4 & 6.9 \\
Modulus of elasticity $\left(\mathrm{N} / \mathrm{mm}^{2}\right)$ & 12,135 & 9.4 \\
Poisson's ratio & 0.23 & 6.8 \\
\hline
\end{tabular}

Table 4 Compressive strength, modulus of elasticity and Poisson's ratio for all test series.

\begin{tabular}{|c|c|c|c|c|c|}
\hline $\begin{array}{l}\text { Determined value } \\
\text { series symbol }\end{array}$ & Kind of steel & $\begin{array}{l}\text { Percentage of } \\
\text { armature (\%) }\end{array}$ & $\begin{array}{l}\text { Compressive } \\
\text { strength }\left(\mathrm{N} / \mathrm{mm}^{2}\right)\end{array}$ & $\begin{array}{l}\text { Modulus of elasticity } \\
\left(\mathrm{N} / \mathrm{mm}^{2}\right)\end{array}$ & Poisson's ratio \\
\hline A & - & - & 14.08 & 13,910 & 0.21 \\
\hline BI & Smooth bars & About 0.05 & 16.22 & 14,440 & 0.20 \\
\hline BII & Smooth bars & About 0.1 & 13.98 & 14,600 & 0.23 \\
\hline CI & Spiral twisted bars & About $0.05^{*}$ & 15.13 & 12,250 & 0.13 \\
\hline CII & Spiral twisted bars & About $0.1 *$ & 13.26 & 13,260 & 0.15 \\
\hline DI & Woven wire mesh & About 0.05 & 17.30 & 12,470 & 0.15 \\
\hline DII & Woven wire mesh & About 0.1 & 17.53 & 12,180 & 0.15 \\
\hline EI & Welded wire mesh & About 0.05 & 19.22 & 12,420 & 0.13 \\
\hline EII & Welded wire mesh & About 0.1 & 19.83 & 13,640 & 0.13 \\
\hline FI & Truss type & About 0.05 & 14.3 & 10,779 & 0.18 \\
\hline FII & Truss type & About 0.1 & 17.6 & 11,830 & 0.16 \\
\hline
\end{tabular}

*Percentage of reinforcement after outside diameter.

masonry wallettes is shown. The compressive strength of unreinforced specimens is about $14.08 \mathrm{~N} / \mathrm{mm}^{2}$ and is about $10 \%$ lower than obtained from standard specimens according to Ref. [15], as shown in Table 3.

The comparison of the resultant stress-strain $(\sigma-\varepsilon)$ relationships for all unreinforced models ("A" series) and masonry specimens (according to the standard [15]) is shown in Fig. 3. The initial part of both curves is quite similar. The ultimate (maximum) value of compressive stress is greater for the smaller (EC-6 Standard) specimens. The tangent angle of inclination with regard to the $\sigma-\varepsilon$ curve for models of "A" series 
decreases more quickly than for the standards' specimens, where it is nearly stable up to about $85 \%$ of ultimate compressive strength. The graphs of average values of $\sigma-\varepsilon$ relationships for all test series are shown in Fig. 4.

\section{Analysis}

\subsection{Models with Longitudinal Bed Joint Reinforcement}

The comparison of the compressive strength values of reinforced wallettes with longitudinal bars with unreinforced specimens (Table 4) shows that the increase of strength was only a small percentage for models of $\mathrm{BI}$ and $\mathrm{CI}$ series, about $15 \%$ and $7.5 \%$, respectively. However, in models of BII and CII series (bigger percentage of reinforcement) some decrease of compressive strength was observed. A more significant decrease of strength was obtained for spiral twisted bar reinforced models (CII). The decrease of the compressive strength of the more strongly reinforced elements $(\rho=0.1 \%)$ is connected with a change in the form of their failure. In unreinforced models, first cracks appeared at about $40-50 \%$ of the maximum

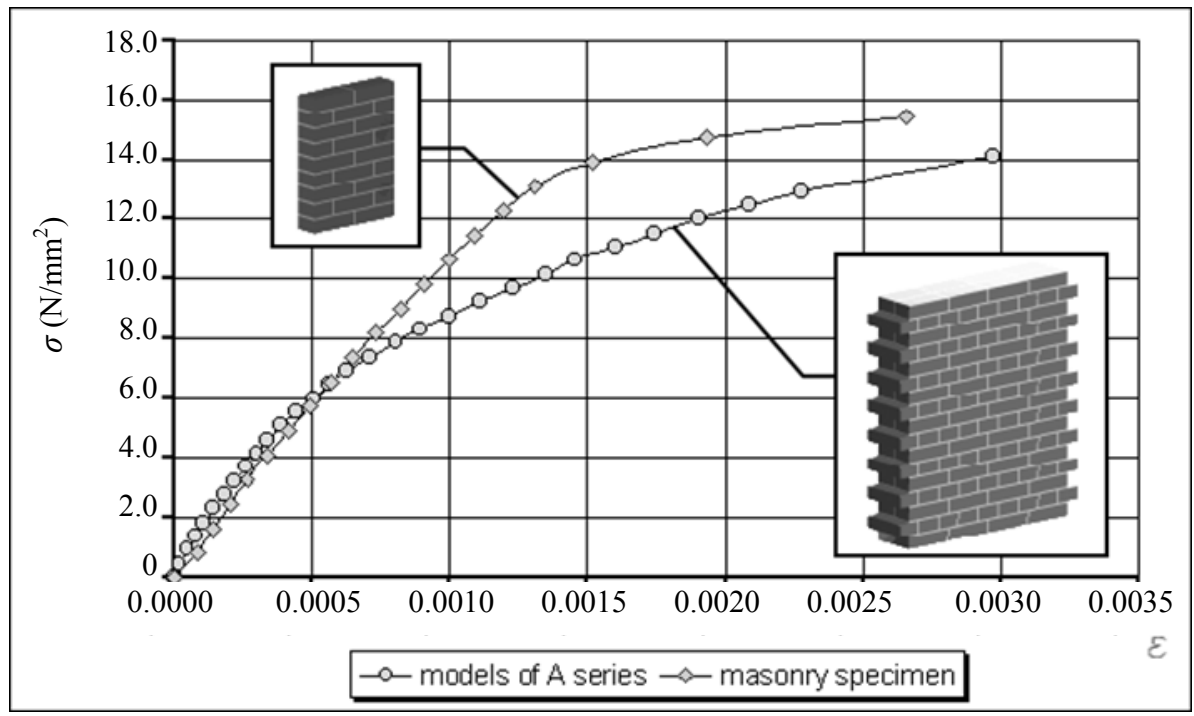

Fig. 3 The $\sigma-\varepsilon$ relationship for unreinforced models: "A" series and EC-6 masonry standards' specimens.

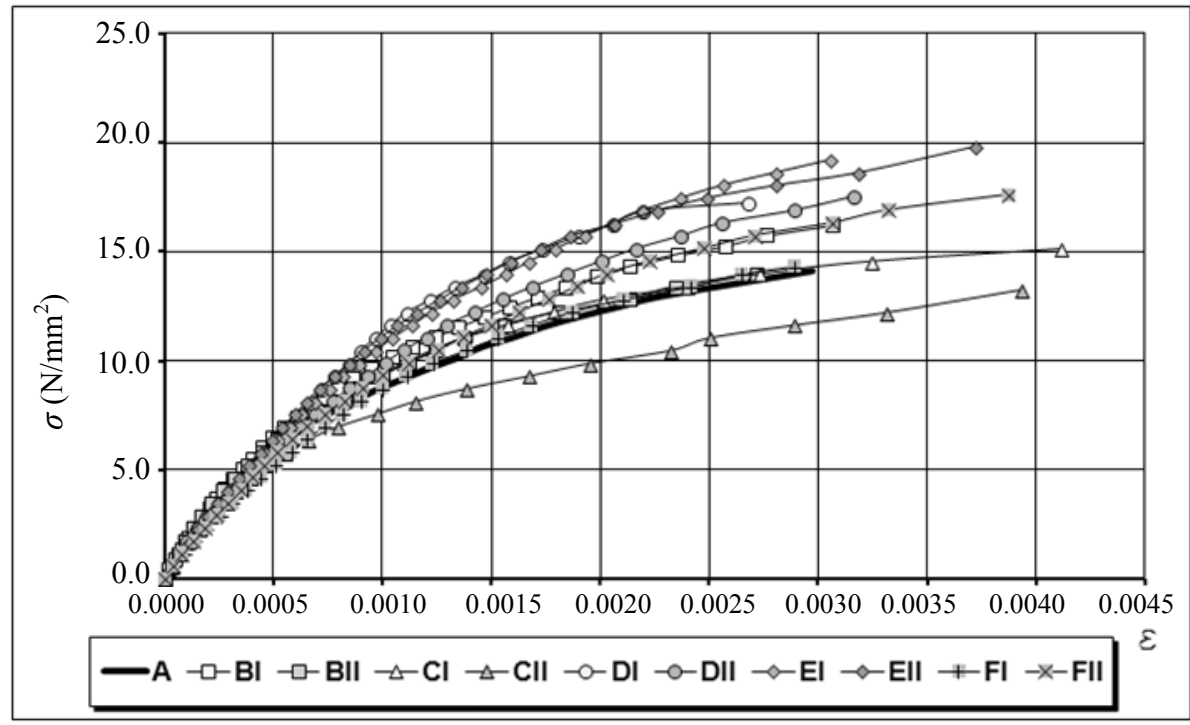

Fig. 4 Graphs of average $\sigma-\varepsilon$ relationships for all test series. 
compressive stress. All cracks had a generally vertical direction. In agreement with Hilsdorf theory, the masonry units cracked first. Then, as the load increased the cracks included head joints of the upper and lower neighbouring brick courses and as a consequence, the wallette divided into a few separate pillars (Fig. 5a). Failure of specimens with longitudinal reinforcement was quite different. All models were split into two separate leaves by an internal crack (as shown in Fig. $5 b)$. The decrease of strength, which is greater for reinforced specimens with the smooth bars, is related to the appearance of the notch effect, which is connected with a stiff inclusion, in shape of bars, in weak mortar joints. All elements with the smaller percentage of reinforcement (BI and $\mathrm{CI}$ series) were characterized by a larger number of cracks, which also had a larger width than observed in models of BII and CII series. In models of BII series $(\rho=0.1 \%)$ the local spalling of the masonry surface in the area of bars' location was observed.

Some graphs displaying an average stress range (from the first crack appearance to failure) is presented in Fig. 6. Elements reinforced with the spiral bars cracked under greater stress levels than elements reinforced with smooth steel rods. Cracking of models reinforced with spiral bars took place with almost the

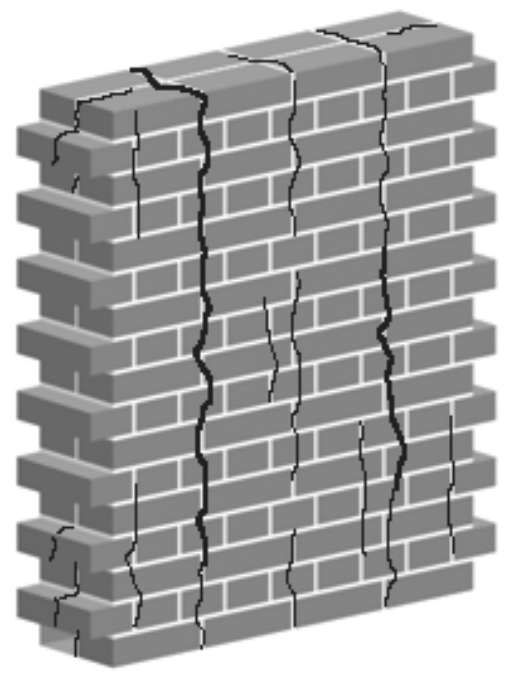

(a) same stress level as for unreinforced models. The stress level corresponding with crack appearance of reinforced models was lower than obtained for unreinforced specimens. The first crack in reinforced (using longitudinal bars) models always appeared in a different place to that in the unreinforced elements. Graphs of steel deformation in relation to compressive strength level in the wallettes are presented in Fig. 7. The first to strain were the spiral rods (larger adherence of to mortar in joint). The rods in masonry with a greater percentage of reinforcement $(\rho=0.1 \%)$ stretched earlier. The comparison of the strength of tensile rods located in the masonry with $\sigma_{t}{ }^{-\varepsilon}$ relationship obtained from the smooth rod tensile tests are shown in Fig. 8. For smooth rods in the wall with a percentage about $0.05 \%$ (BI series), the level of tensile stress of $53 \%$ of the yield point of steel were obtained. Whereas for smooth bars in masonry with double that percentage (about $0.1 \%$ in BII series), the level of tensile stress was about $39 \%$ of the yield point of steel. The designated level of tensile stress in spiral bars was $49 \%$ of the yield point of steel for models of CI series and $30 \%$ for CII series. The comparison of both types of bed joint reinforcement shows that spiral bars are more effective. That kind of reinforcement combined better with the mortar in the walls' joints (Fig. 7) and

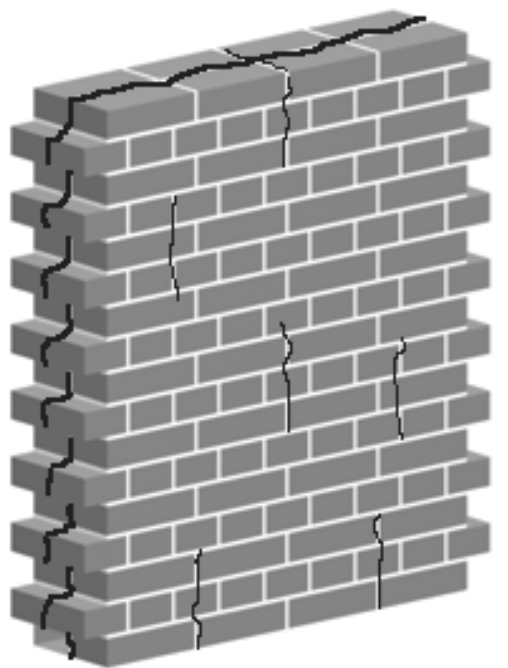

(b)

Fig. 5 Typical crack pattern of tested elements: (a) unreinforced and with wire mesh reinforcement; (b) reinforced with longitudinal bars and truss type. 


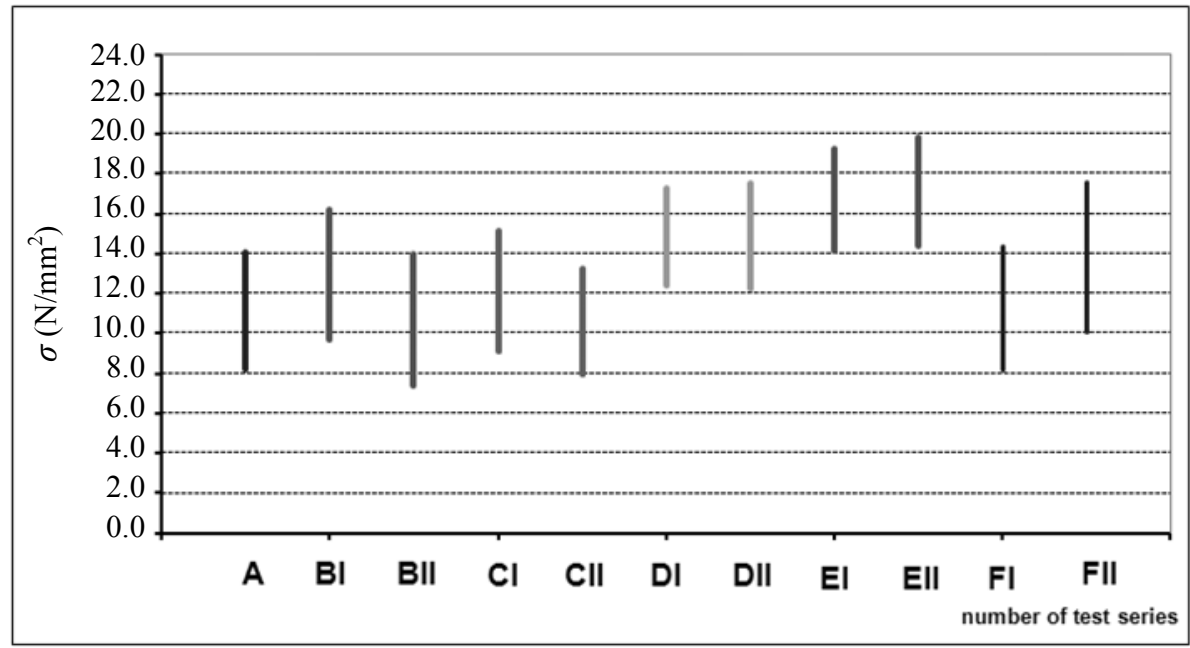

Fig. 6 Graph of stress interval from first crack to failure for all test series.

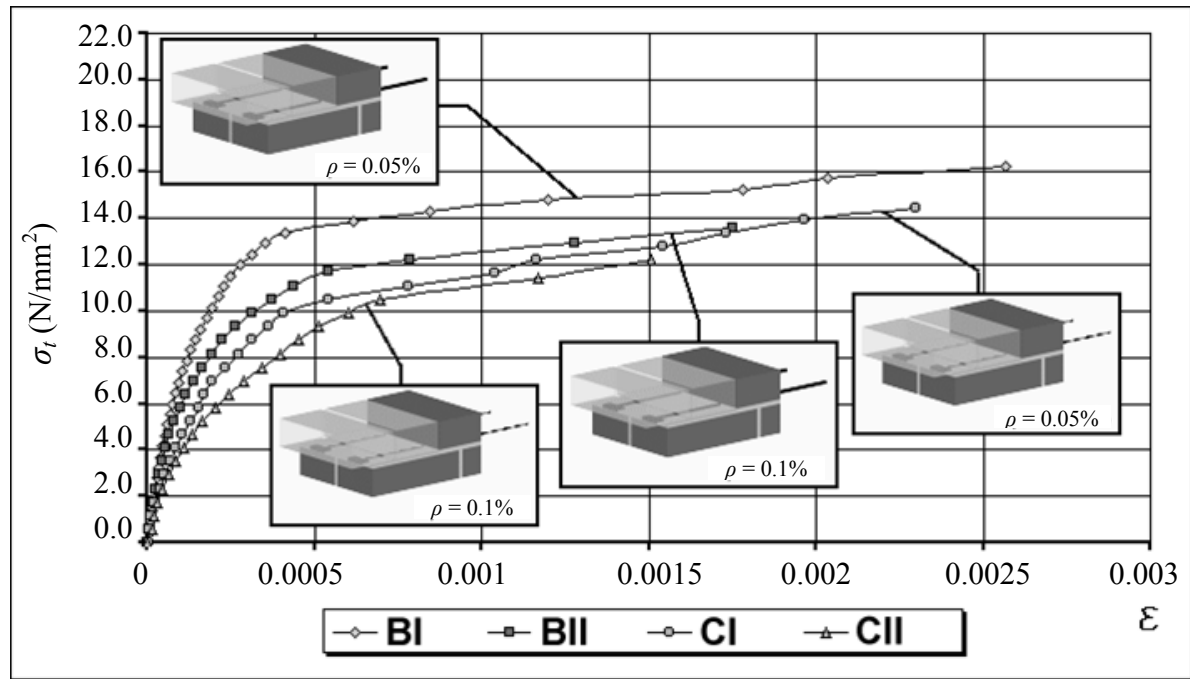

Fig. 7 Graph of steel deformation in relation to compressive stress level for " $B$ " and " $C$ " series.

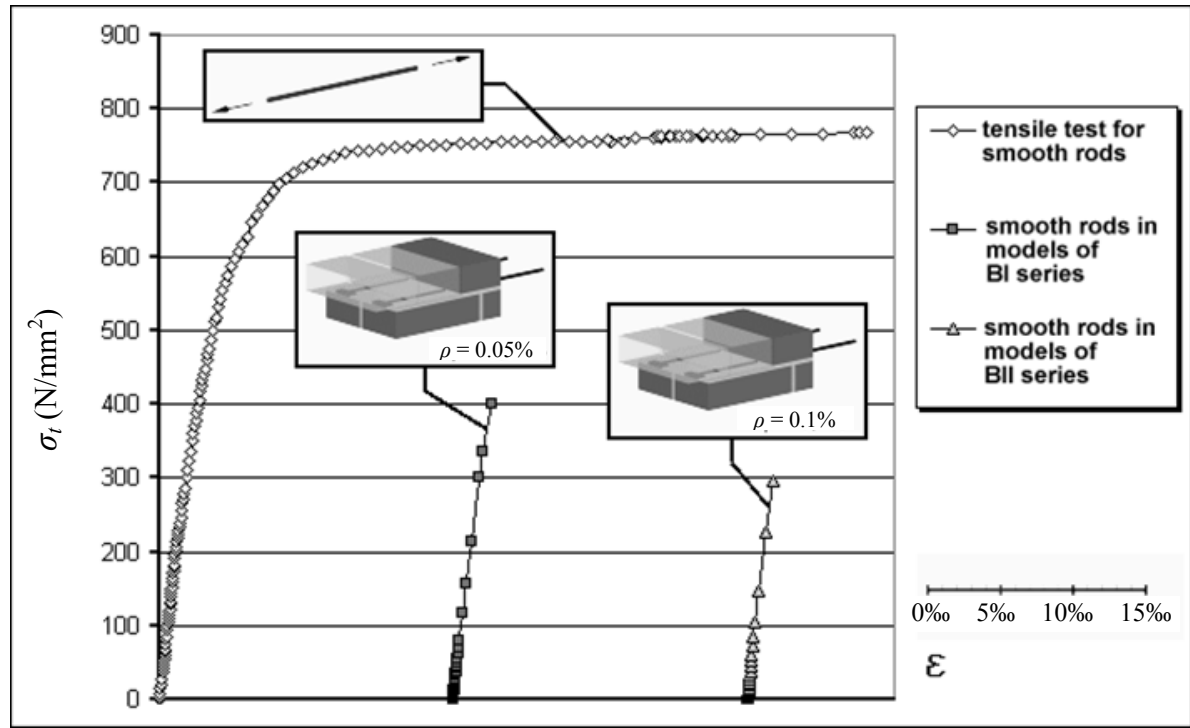

Fig. 8 Comparison of $\sigma_{t}-\varepsilon$ relationships for rods located in masonry with $\sigma_{t}-\varepsilon$ obtained from rod tensile tests. 
did not change the value of modulus of elasticity in comparison to the unreinforced models (Table 4). Moreover, it has much better influence on the crack resistance (Fig. 6). The increase of strength obtained for models with the lower reinforcement percentage (CI) towards the elements reinforced with smooth steel (BI) could be explained by its three times lower area than the spiral bars. As in case of reinforcement in the shape of smooth bar (BII), there was found to be some decreasing of load capacity for series with greater $(\rho=$ $0.1 \%$ ) reinforced percentage (CII).

\subsection{Models with Wire Mesh Reinforcement}

Reinforcement in the shape of wire mesh gives a more significant growth of load capacity in comparison to reinforcement in the form of longitudinal bars (Table 4). In the case of the lower reinforcement percentage, the growth of the load capacity for woven wire mesh reinforcement (DI) was about $23 \%$ and for welded wire mesh (EI) about 37\%. Doubling the reinforcement percentage caused a slight growth of load capacity. For walls reinforced with the greater percentage of woven wire mesh (DII), the authors obtained a growth of the load capacity of over $25 \%$ in comparison to the unreinforced models. For specimens with welded wire mesh (EII), the load capacity increased even more by about $41 \%$. The failure shape of tested wallettes was typical - all specimens were divided by vertical cracks into a few pillars. It is an identical situation to that observed for unreinforced models (Fig. 5a). Using a wire mesh bed joint reinforcement eliminated the disadvantageous crack pattern which was observed for elements with longitudinal bar reinforcement. In the models of " $D$ " series, the failure was connected with the reinforcement anchorage and vertical cracks in the anchorage planes. In elements of "E" series, the failure by a few vertical cracks corresponded with the moment of breaking the reinforcement (two longitudinal bars). The wire mesh worked with the masonry much better than longitudinal bars because the mesh limited the mortar's deformation in the whole horizontal plane. The deformation of longitudinal and lateral bars in the "DI" models as a function of compressive stress is shown in Fig. 9. It shows that longitudinal and lateral bars worked in a similar way. That is why the influence of the wire mesh longitudinal bars is very important for masonry strength. The comparison of the deformation of the longitudinal bars of the " $\mathrm{B}$ " and " $\mathrm{C}$ " series with wire mesh longitudinal $4 \mathrm{~mm}$ diameter bars (Fig. 9) shows that the deformation of wire mesh bars is less by half.

Reinforcement in the form of wire mesh also has a greater influence on masonry crack resistance. The limitation of mortar deformation has a significant

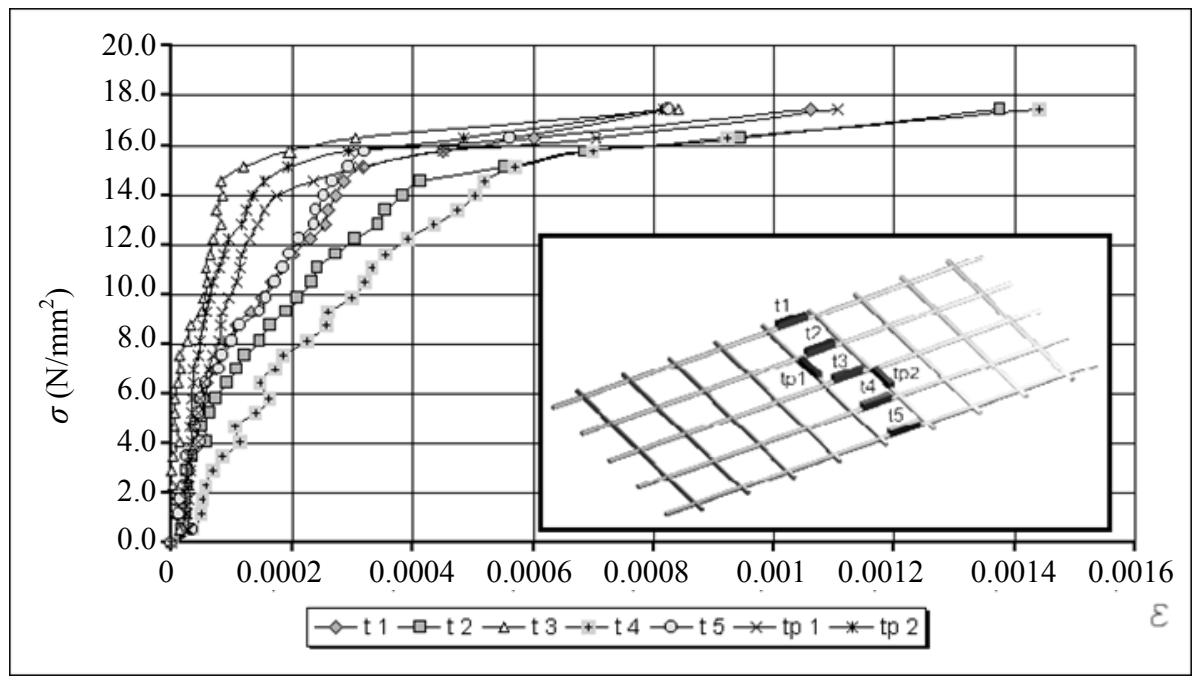

Fig. 9 Steel deformations for lateral and longitudinal bars in relation to compressive stress for models of " $D$ " series. 
influence on the level of stress corresponding with the first crack appearance (Fig. 6). In the case of the "D" series, first cracks were observed for a compressive stress level $\sigma_{c}$ of about $13 \mathrm{~N} / \mathrm{mm}^{2}$, whereas the elements of the "E" series were cracked at $\sigma_{c}$ of about $14.3 \mathrm{~N} / \mathrm{mm}^{2}$, a result similar to the unreinforced elements.

\subsection{Models with Truss Type Reinforcement}

The comparison of values of the compressive strength of unreinforced and reinforced F series (Table 4) was found that small percentage of the reinforcement in FI specimens does not have an effort on carrying capacity of masonry and the bigger percentage (FII specimens) increases about $25 \%$ of the strength. Reinforcement reduces masonry modulus of elasticity and Poisson's ratio.

Bed joint reinforcement caused the change of masonry failure. Destruction was always into internal joint. All models were split into two independent shields (Fig. 10). There were cut out the reinforcements from every specimens after finishing the researches. It was said that the tensile failure was done to the continuous wire diagonal (Fig. 11), what explains the cracks along the internal joint.

The results of the measurement of the strains of reinforcing bars with both percentages showed that the strains of the longitudinal bars and the continuous wire diagonal are similar. The tensile failure of the continuous wire diagonal results from the smaller diameter. It is clear that using the continuous wire diagonal with the higher diameter may cause the increase the crack resistance and compressive strength of masonry. Fig. 12 are displayed exemplary reinforcement strains in the function of masonry compressive strength.
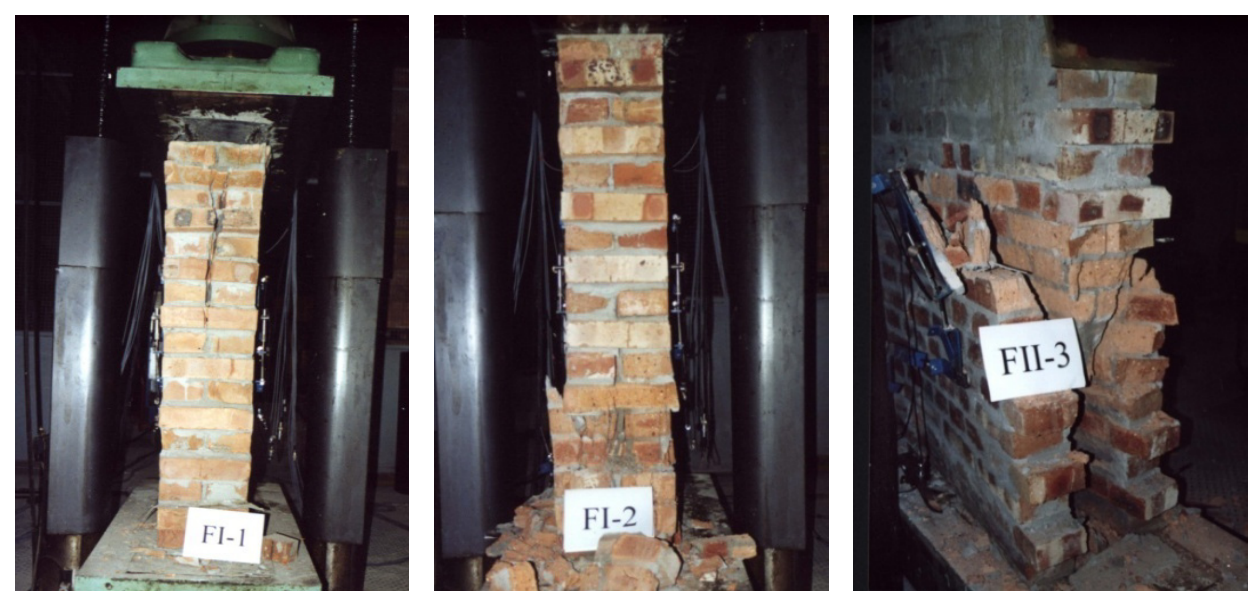

Fig. 10 Failure of FI series models.

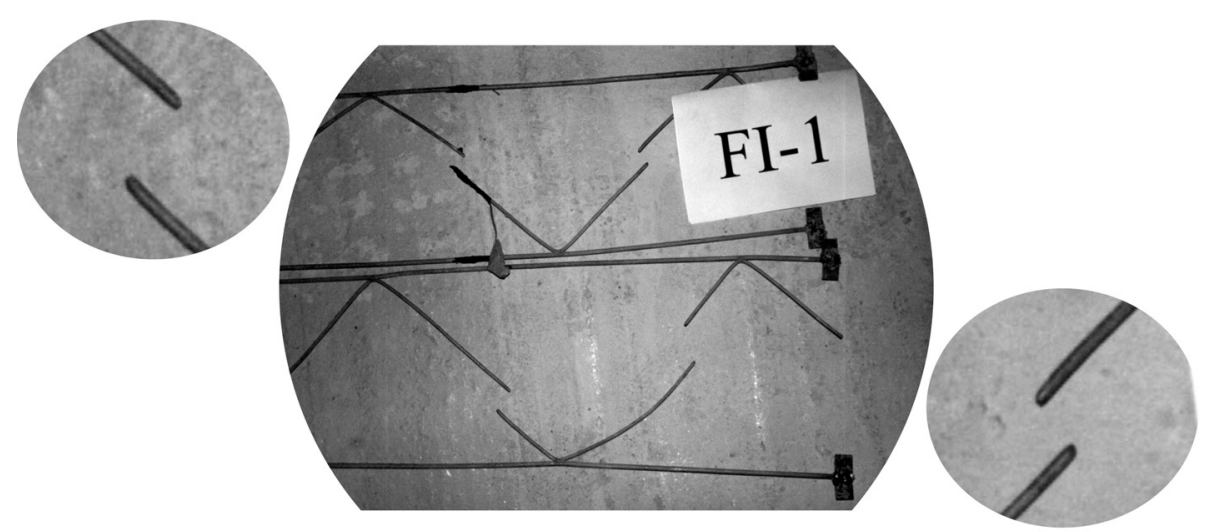

Fig. 11 Truss type reinforcement cut out from specimen after finishing the researches. 


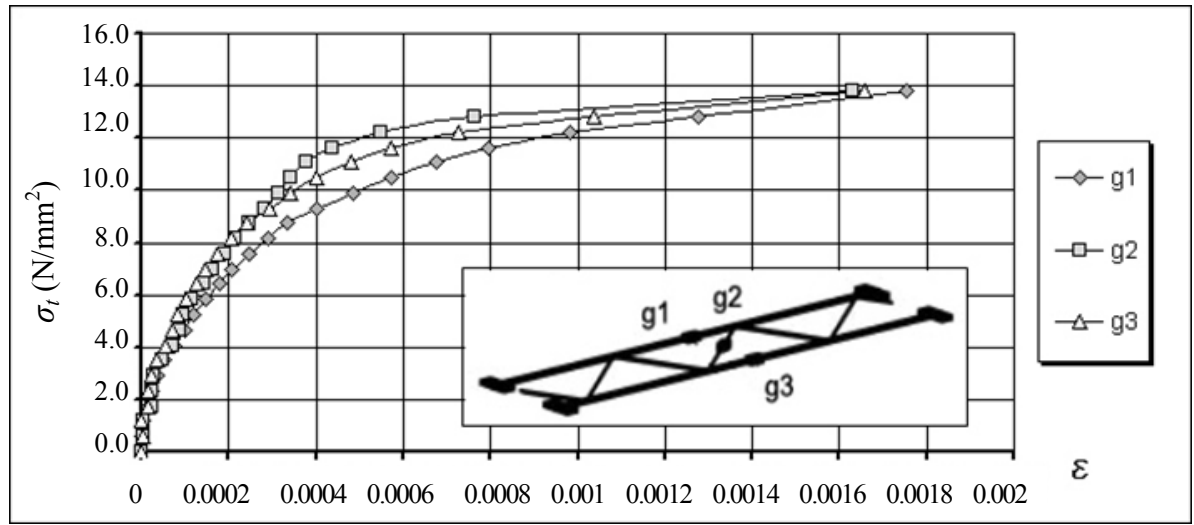

Fig. 12 Bars steel deformations in relation to compressive stress for models of " $F$ " series.

\section{Conclusions}

The investigations carried out showed the significant influence of bed joint reinforcement on the behavior of masonry wallettes subjected to axial compressive loads. The analysis of tests results given above leads the authors to formulate the following conclusions:

(1) Using bed joint reinforcement in the shape of longitudinal bars (smooth and spiral twisted) is not very beneficial. For $\rho=0.05 \%$ a slight growth of load capacity in comparison with unreinforced specimens was determined. Unfortunately, for double the $\rho$ value $(\rho=0.1 \%)$ a decrease of the load capacity was noted;

(2) A very disadvantageous failure shape (dividing of the wall into two separate leaves) was observed for specimens reinforced with longitudinal bars and truss type;

(3) A more positive effect is given by the use of woven or welded wire mesh bed joint reinforcement. For reinforcement percentage $\rho=0.05 \%$, about $23 \%$ (woven wire mesh) and about 37\% (welded wire mesh) growth of load capacity with reference to unreinforced specimens was obtained. Increasing of $\rho$ value (up to $\rho$ $=0.1 \%$ ) gave a further slight growth of load capacity;

(4) The failure shape was typically the same as in the case of unreinforced specimens - dividing the masonry wallettes by vertical cracks into a few separate pillars;

(5) In models with truss type reinforcement small reinforcement percentage ( $\rho=0.05 \%$ ) did not effect the mechanical features of the masonry. Double increase of the reinforcement $(\rho=0.1 \%)$ caused the enlargement of the capacity (about 25\%) and crack resistance (about $23 \%)$;

(6) The usage of reinforcement has influence on the failure of models: limited scratching of front surfaces of elements and destruction in internal joint.

\section{References}

[1] K.J. Schneider, N. Weickenmeier, Present Masonry Constructions, Werner Verlag GmBH \& Co.KG, Düsseldorf, Berlin, 2000.

[2] J.E. Amrhein, Reinforced Masonry Engineering Handbook, Clay and Concrete Masonry, Masonry Institute of America, CRC Press Boca Raton, New York, 1998.

[3] L. Drobiec, About the necessity of using appropriate reinforcement in the wall bed joint, Monography Reprocity Resume, Faculty of Civil Engineering, Silesian University of Technology, Gliwice, 2008, pp. 89-95.

[4] P. Timperman, J.A. Rice, Bed joint reinforcement in masonry, in: Proceedings of the Fourth International Masonry Conference, British Masonry Society, London, 1995, pp. 451-453.

[5] O. Pfeffermann, G. van de Loock, 20 Years experience with bed joint reinforced masonry in Belgium and Europe, in: Proceedings of the 9th International Brick/Block Masonry Conference, Berlin, Germany, 1991, pp. 427-436.

[6] P. Schiessl, S. Schmidt, Reinforced masonry-Discussion about the way of building, Beratende Ingenieure 7 (8) (1989) 28-31. (in German)

[7] G. van de Loock, Special reinforcement of masonry, Ziegelindustrie International 1 (1980) 16-18. (in German)

[8] T. Mader, Reinforced masonry in practice bewehrtes mauerwerk in der praxis, Das Bauzentrum 5 (1993) 65-66. (in German)

[9] W. Jäger, L. Drobiec, Bed joint reinforced masonry under vertical compression, Mauerwerk 6 (2006) 252-257. (in 
German)

[10] R. Pohl, The reinforcement increases the way of using the brick walls, Das Bauzentrum 9 (1996) 125-128. (in German)

[11] O. Pfeffermann, B. van Hoorickx, Some practicular applications of reinforced masonry in Belgium, in: Proceedings of the 12th International Brick/Block Masonry Conference, Madrid, Spain, 2000, pp. 1437-1446.
[12] BS EN 1015-11:1999, EN 1015 Methods of Test for Mortar for Masonry, British Standards Institution, 1999.

[13] EN 772-1 Methods of Test for Masonry Units-Part 1: Determination of Compressive Strength, 2000.

[14] PN-91/H-04310, Static Tensile Testing of Metals, Polish Code, 1991. (in Polish)

[15] EN 1052-1 Method of Test for Masonry, Determination of Compressive Strength, Brussels, Belgium, 1999. 